\title{
Understanding the role of basin architecture on the geochemical evolution of fluids in the Paradox Basin using noble gases.
}

\author{
REBECCA L TYNE ${ }^{1}$, PETER H BARRY ${ }^{2}$, ANNIE CHENG ${ }^{1}$, \\ JI-HYUN KIM ${ }^{3}$, DARREN HILLEGONDS ${ }^{1}$, JENNIFER \\ MCINTOSH $^{3}$ AND CHRIS J BALLENTINE ${ }^{1}$ \\ ${ }^{1}$ University of Oxford \\ ${ }^{2}$ Woods Hole Oceanographic Institution \\ ${ }^{3}$ University of Arizona \\ Presenting Author: rebecca.tyne@earth.ox.ac.uk
}

Groundwater is crucial in controlling the migration, accumulation and storage of hydrocarbons, $\mathrm{CO}_{2}$ and other less abundant gases (e.g., helium and hydrogen). The Paradox Basin, in the Colorado Plateau, is encompassed by a thick evaporite unit (Paradox Formation) and has exhibits extensive evidence for paleofluid flow, including sandstone bleaching, as well as hydrocarbon, $\mathrm{CO}_{2}$ and $\mathrm{He}$ reservoirs. The complex nature of the fluid flow and interactions within this basin, make it an ideal location to investigate the role of basin architecture on crustal fluid migration and geochemistry.

Noble gases are powerful conservative tracers of subsurface fluid flow. Any fractionation of noble gases in crustal fluids are the result of physical mechanisms (e.g., diffusion) and as such, they have been extensively used to characterise fluid provenance, migration and interactions within sedimentary basins.

We present noble gas data from the Paradox Basin, across 8 different stratigraphic units, from both groundwater and hydrocarbon wells. We demonstrate using ${ }^{3} \mathrm{He} /{ }^{4} \mathrm{He},{ }^{21} \mathrm{Ne} /{ }^{22} \mathrm{Ne}$ and ${ }^{40} \mathrm{Ar} /{ }^{36} \mathrm{Ar}$ ratios that the noble gases are predominantly groundwater-derived, with radiogenic overprinting. There is a marked difference in noble gas signatures below and above the Paradox Formation, with the strongest radiogenic noble gas ratios occurring below the evaporite. Radiogenic noble gas concentrations are shown to increase with stratigraphic age; however, the concentrations are higher than can be explained solely by in-situ production. We developed a vertical 1D ${ }^{4} \mathrm{He}$ diffusion reference model to investigate the nature of the basement helium flux and the extent of diffusion throughout the units in order to simulate the observed ${ }^{4} \mathrm{He}$ profiles. We find that the evaporite is an impermeable barrier to He migration and an additional basement $\mathrm{He}$ flux is required. Additionally, we developed an atmospheric noble gas phase fractionation model to investigate fluid interactions and find evidence of groundwater flushing both above and below the Paradox Formation, consistent with findings from the hydrogeochemistry and ${ }^{81} \mathrm{Kr}$ data $[1,2]$. Both models further demonstrate the role of the Paradox Formation in controlling fluid composition and paleofluid flow in the basin.

[1] Kim et al., 2019 GSA abstract. [2] Kim et al., 2020 Goldschmidt abstract. 